\title{
Tentorial Dural Fistulas: Endovascular Management and Description of the Medial Dural-Tentorial Branch of the Superior Cerebellar Artery
}

J.V. Byrne and M. Garcia

\begin{abstract}
BACKGROUND AND PURPOSE: TDAVFs are uncommon causes of spontaneous intracranial hemorrhage. A retrospective review of their management was performed after repeatedly observing a previously under-recognized medial dural-tentorial branch of the SCA.
\end{abstract}

MATERIALS AND METHODS: Thirteen patients were diagnosed with TDAVFs by CT/MR imaging and DSA during a 5.8-year period. Seven patients presented after intracranial hemorrhage. Twelve patients were treated endovascularly, and one, surgically.

RESULTS: Eleven TDAVFs were located in the midline ( 7 at the falx cerebelli and 4 at the torcular), and 2 were petrotentorial. All torcular TDAVFs were associated with sinus thrombosis and showed bidirectional drainage relative to the tentorium. No sinus thrombosis was seen in the falx cerebelli subtype, which drained infratentorially only, except in 1 patient who had had unrelated surgery previously. Venous drainage was directly to cortical veins except for 1 petrotentorial and 2 torcular TDAVFs. A branch of the SCA, the medial dural-tentorial artery, was observed in 5 midline TDAVFs. Its anatomy was defined with selective angiography. Endovascular therapy resulted in a cure in 5 and subtotal occlusion in 6 , and staged treatment is ongoing in 1 patient. One patient was cured after surgery.

CONCLUSIONS: TDAVFs frequently cause intracranial hemorrhage and therefore warrant treatment. Endovascular therapy proved effective in this series, and arteriography was essential for understanding the various fistula subtypes and for treatment planning. We emphasize the importance of recognizing the medial dural-tentorial artery of the SCA with its characteristic course along the tentorium on angiography. This artery should be included in future anatomic descriptions of the cranial blood supply.

ABBREVIATIONS: AICA = anterior inferior cerebellar artery; ADS = artery of Davidoff and Schechter; DAVF = dural arteriovenous fistula; SCA = superior cerebellar artery; TDAVF $=$ tentorial dural arteriovenous fistula

D ural arteriovenous fistulas account for $10 \%-15 \%$ of all intracranial vascular shunts. ${ }^{1,2}$ The TDAVF is a rare subgroup, constituting $<4 \%$ of DAVFs. ${ }^{1,3-6}$ TDAVFs are most frequently diagnosed in middle-aged men, ${ }^{2,4,5,7}$ unlike DAVFs elsewhere, which are more frequent in elderly women. ${ }^{8,9}$ Spontaneous intracranial hemorrhage is the usual presenting symptom because cortical venous reflux is common. ${ }^{4,6,7,10}$ Otherwise, diagnosis relies on imaging because neurologic symptoms are nonspecific and nonlocalizing. ${ }^{6,11-16}$

TDAVFs are generally considered separate from DAVFs located along the transverse and sigmoid sinuses despite their proximity. This distinction appears to be historic and is based on anatomic, symptomatic, and therapeutic differences. Anatomically,

Received October 29, 2012; accepted after revision December 27.

From the Nuffield Department of Surgical Sciences, University of Oxford, Oxford UK.

Please address correspondence to James V. Byrne, MD, Department of Neuroradiology, West Wing, John Radcliffe Hospital, Headington, Oxford OX3 9DU, UK;

e-mail: james.byrne@nds.ox.ac.uk

http://dx.doi.org/10.3174/ajnr.A3519
DAVFs primarily involve the single-layer dura of the calvaria, while TDAVFs occur in the reflected (double-layer) dura of the tentorium and its attachments. Because TDAVFs usually drain to cortical veins, invasive treatment is recommended, irrespective of presentation. ${ }^{4,6,7,10}$ Treatment is traditionally by surgical resection but access is often difficult, ${ }^{10}$ and endovascular therapy is a recognized and increasingly used alternative, either alone or in combination with surgery. ${ }^{17}$ Another alternative is stereotactic radiosurgery, which has been reported in feasibility studies ${ }^{18,19}$ and may be a useful adjunct to endovascular treatment.

Due to their rarity, the number of reports describing TDAVFs and their management is limited. Nevertheless, several classification systems have been proposed on the basis of location and venous drainage patterns. ${ }^{5,7}$ The arterial supply is not an important feature in these descriptions, but with the increasing use of endovascular treatment, it is clearly important and may be helpful in classification and distinguishing TDAVFs from DAVFs located at the tentorial margins.

We present 13 TDAVFs and classify them according to location and overall vascular supply. Special attention is drawn to an 
Table 1: Patient details and presenting symptoms

\begin{tabular}{|c|c|c|c|c|}
\hline No. & Age (yr) & Sex & Clinical Presentation & Initial CT/MR \\
\hline 1 & 45 & M & Collapse, headache & CT/CTA: ICH posterior fossa, developing hydrocephalus \\
\hline 2 & 64 & M & Unrelated stroke, incidental finding on imaging & $\begin{array}{l}\text { CT/CTA: small subacute ischemic area supratentorially, } \\
\text { dilated abnormal vessels in the posterior fossa }\end{array}$ \\
\hline 3 & 56 & M & Collapse, vomiting, dysarthria, blurred vision & CT/CTA: ICH posterior fossa, developing hydrocephalus \\
\hline 4 & 65 & $\mathrm{~F}$ & Transient arm weakness & MRI: abnormal vessels with venous engorgement \\
\hline 5 & 65 & M & Acute-onset headache & $\begin{array}{l}\text { CT/CTA: SAH in the posterior fossa with ventricular } \\
\text { spread, hydrocephalus }\end{array}$ \\
\hline 6 & 64 & $\mathrm{~F}$ & Hearing loss, tinnitus, diplopia & $\begin{array}{l}\text { MRI: abnormal vascular structures in the right-side } \\
\text { posterior fossa }\end{array}$ \\
\hline 7 & 64 & $\mathrm{~F}$ & Headache, progressive mental confusion, dysphasia & CT/CTV: engorged leptomeningeal veins \\
\hline 8 & 66 & M & Visual disturbance and hemianopia & MRI: multiple congested intracranial veins \\
\hline 9 & 58 & M & Acute-onset headache & CT/CTA: posterior fossa SAH \\
\hline 10 & 60 & $\mathrm{~F}$ & Severe headache, vertigo & CT/CTA: perimesencephalic SAH \\
\hline 11 & 64 & M & Collapse, vomiting, aphasia & $\mathrm{CT}$ : posterior fossa SAH with intraventricular spread \\
\hline 12 & 56 & $\mathrm{~F}$ & Pulsatile tinnitus & MRI/MRA: abnormal vessels \\
\hline 13 & 60 & M & Acute-onset headache & CT: cerebellar ICH \\
\hline
\end{tabular}

Note:-CTV indicates venous phase CTA.

under-recognized medial dural-tentorial branch of the superior cerebellar artery, which has not been previously demonstrated by selective arteriography, to our knowledge. We describe the main features of this artery to emphasize its importance in future anatomic descriptions of TDAVFs.

\section{PATIENTS AND METHODS \\ Patients}

A search of our institutional data base identified 13 patients with TDAVFs presenting between January 2007 and September 2012. DAVFs of the transverse or sigmoid sinuses and other posterior fossa locations not supplied by tentorial arteries were excluded. All patients underwent initial CT/CTA and/or MR imaging/MRA, as well as subsequent DSA before treatment. The mean age was 59.8 years (age range, 45-66 years) with a male/female ratio of 8:5 (Table 1).

\section{Presentation}

Symptoms were the following: headache $(n=7)$, tinnitus $(n=2)$, visual disturbances $(n=3)$, transient weakness $(n=1)$, and progressive confusion $(n=1)$. One patient presented after imaging for coincidental stroke. Seven patients presented after spontaneous intracranial hemorrhage; 3 were initially unconscious, requiring mechanical ventilation. Imaging showed posterior fossa hemorrhage; principally subarachnoid in 4 , cerebellar in 3, with intraventricular hemorrhage in 4 patients (Table 1).

\section{Angiographic Findings}

TDAVFs were classified by the arteriovenous shunt location (Fig 1). Most were midline and could be separated into torcular $(n=4)$ (Figs 2 and 3 ) and falx cerebelli $(n=7)$ (Figs 4 and 5). The remaining 2 fistulas were at lateral petrotentorial locations along the petrous attachment of the tentorium. All drained to subarachnoid/cortical veins and were classified as type III or IV fistulas, except 1 petrotentorial and 2 torcular fistulas that were graded type II $\mathrm{a}+\mathrm{b}$ according to Cognard et al. ${ }^{20}$ In 2 of the torcular fistulas, bilateral occlusion of the lateral/sigmoid sinuses was present, and in the other 2, complete or partial thrombosis of 1 lateral sinus was evident (Table 2).

The arterial supply demonstrated on DSA is detailed in Table 2. This arose from tentorial branches of the ICA in 8 cases, specifically the meningohypophyseal trunk $(n=7)$ and the inferolateral

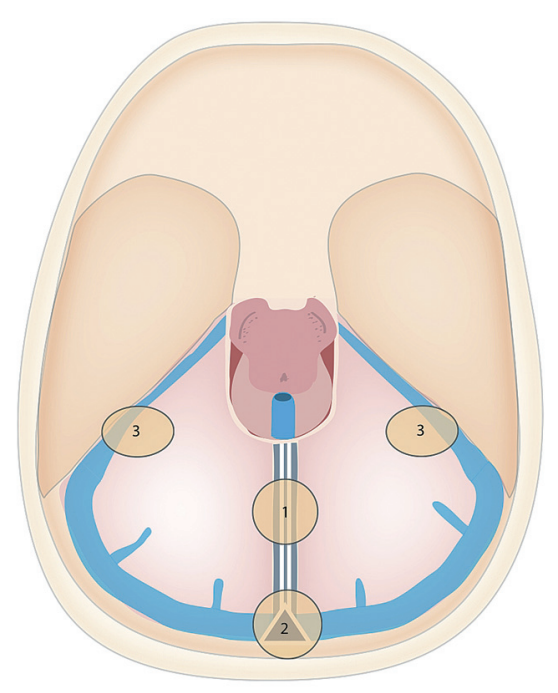

FIG 1. Sites of TDAVFs: $1=$ falx cerebelli, $2=$ torcular, and $3=$ petrotentorial locations.

trunk $n=(1)$; from branches of the external carotid artery in 10 cases, specifically the middle meningeal $(n=8)$, the occipital ( $n=$ $9)$, and the ascending pharyngeal $(n=3)$ arteries; from branches of the vertebral artery in 8 cases, specifically the musculospiral (extradural) branches $(n=3)$ and the posterior meningeal artery $(n=7)$; from branches of the basilar artery, specifically the posterior inferior cerebellar artery $(n=3)$, AICA $(n=2)$, a previously under-recognized medial dural-tentorial branch of the SCA $(n=5)$, and the tentorial branch of the posterior cerebral artery $(n=4)$. In patient 11 , a flow aneurysm arose from a feeding PICA. There was bilateral fistulous supply in 7 patients, principally involving the posterior division of the middle meningeal and occipital arteries.

The tentorial arteries arising from the meningohypophyseal trunk supplied both median and medial-laterally located fistulas. However, the tentorial branch of the posterior cerebral artery, also known as the artery of Davidoff and Schechter, ${ }^{21}$ and the medial dural-tentorial branch of the SCA only supplied fistulas located at the midline and showed the same characteristic courses on lateral DSA projections. The ADS makes a gentle curve, concave 

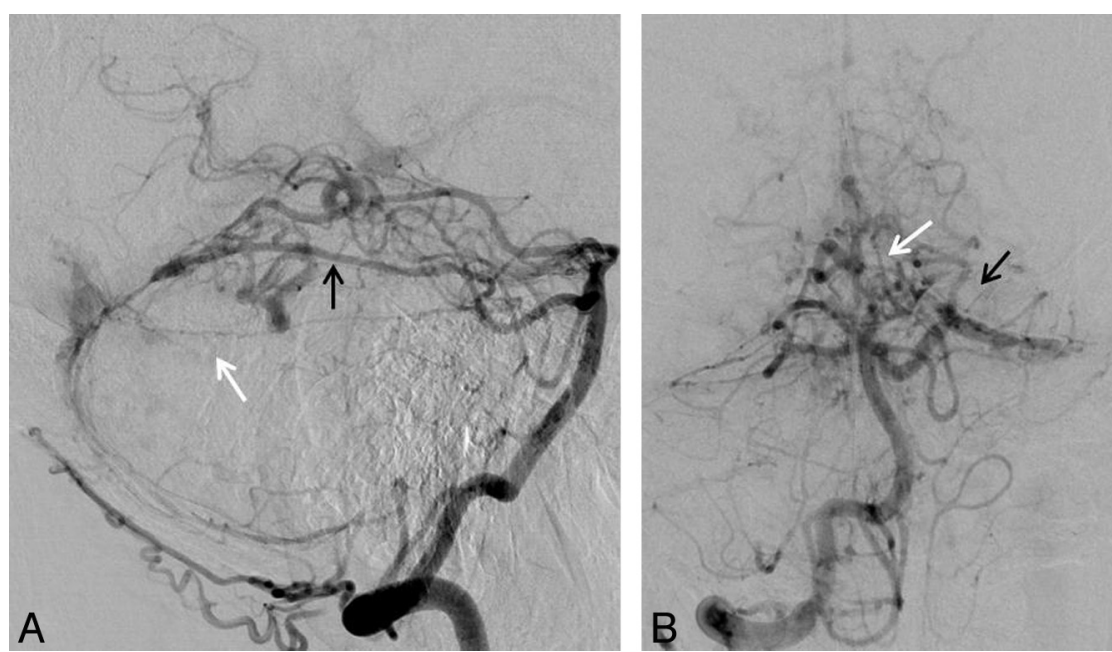

FIG 2. Torcular TDAVF (patient 8). Injections of the right vertebral artery in the lateral $(A)$ and anteroposterior $(B)$ views. Note the medial dural-tentorial branch of the left SCA (white arrow) running below the ADS (black arrow); both arteries are supplying the fistula. Additional supply is seen from the posterior meningeal artery and muscular branches of the extracranial vertebral artery.
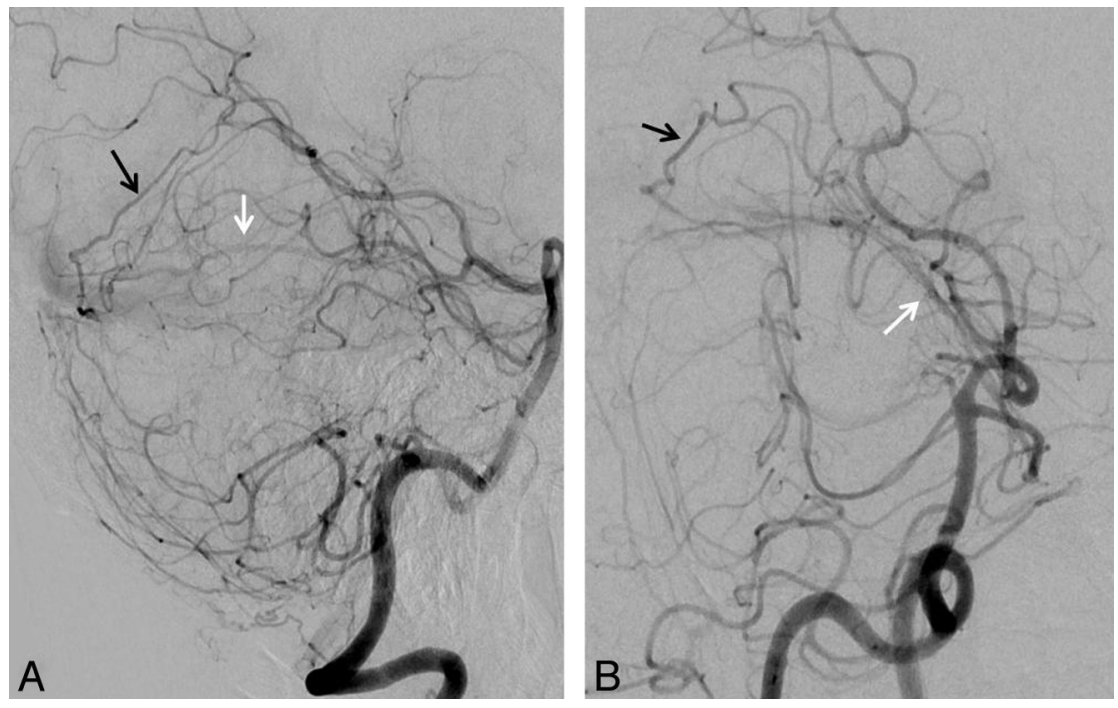

FIG 3. Torcular TDAVF (patient 7). Injections into the left vertebral artery in lateral $(A)$ and the right vertebral artery in lateral-oblique $(B)$ views show the supply to the fistula from the left ADS (black arrows) and the left medial dural-tentorial branch of the SCA (white arrows). There was additional arterial supply from branches of the external carotid artery (not shown).

\section{Endovascular Treatments}

Endovascular therapy was performed in 12 patients ( 1 after fistula recurrence following surgery), and 1 patient was treated by surgery after failed endovascular therapy. Endovascular therapy was performed as single treatments (7 patients) or staged (3 patients underwent 2, and 2 patients 3) treatments. Access was transarterial in 10 or transvenous and transarterial in 2 patients. Embolization was performed with either ethylene-vinyl alcohol, formulated as Onyx (ev3, Irvine, California) or n-butyl cyanoacrylate formulated as Glubran (GEM, Viareggio, Italy). Onyx was used alone in 5, in combination with Glubran in 3, and with coils in 2 patients. Adjuvant coils were used transarterially to reduce blood flow and transvenously to occlude a large venous pouch in treatments of torcular and petrotentorial TDAVFs, respectively. Glubran was used alone to occlude an arterial aneurysm after $\mathrm{SAH}$ in 1 patient.

Procedural complications occurred during 4 endovascular treatments, without causing new symptoms or disability. They comprised 1 arterial dissection, 1 perforation (managed by sealing with Glubran), and 2 microcatheter ruptures (1 without vessel damage and 1 causing Onyx efflux and occlusion of the distal occipital artery) (Table 3).

\section{Treatment Results}

Anatomic. Endovascular therapy achieved complete occlusion of the fistula in 5 and subtotal occlusion in 6 patients. One patient is still in treatment, and the remaining patient (who was treated surgically) was cured (Table 4).

inferiorly, from anterior to posterior, while the more inferiorly lying medial dural-tentorial artery of the SCA has a more horizontal posterior course toward the midpoint of the inferior surface of the straight sinus. Both arteries turn medially posterior to the tentorial hiatus and run toward the midline (Figs 2-5).

None of the fistulas showed supratentorial venous drainage only. The fistulas at the falx cerebelli drained inferiorly to the posterior fossa veins in all cases and additionally to the supratentorial cortical veins in 1 patient. The 4 lesions at the torcular drained to tentorial veins and then to both infra- and supratentorial cortical veins. The petrotentorial fistulas drained to cortical veins above and below the tentorial attachment in 1 patient and only infratentorially in 1 patient (Table 2).
Clinical. Symptoms resolved completely in 3, improved in 6, and are unchanged in 1 patient. Two patients died due to other complications. One patient died 2 weeks after complete occlusion of the fistula due to malignant cerebellar swelling causing brain stem compression despite decompression occipital craniectomy to remove the presenting hematoma. The other patient died 6 months after endovascular treatment due to pulmonary edema. The last patient is still recovering after emergency treatment of a ruptured flow-related PICA aneurysm. The patient who remains symptomatic showed temporary improvement after successful surgery but subsequently developed headache without evidence of hydrocephalus or recurrence on imaging (Table 4). 

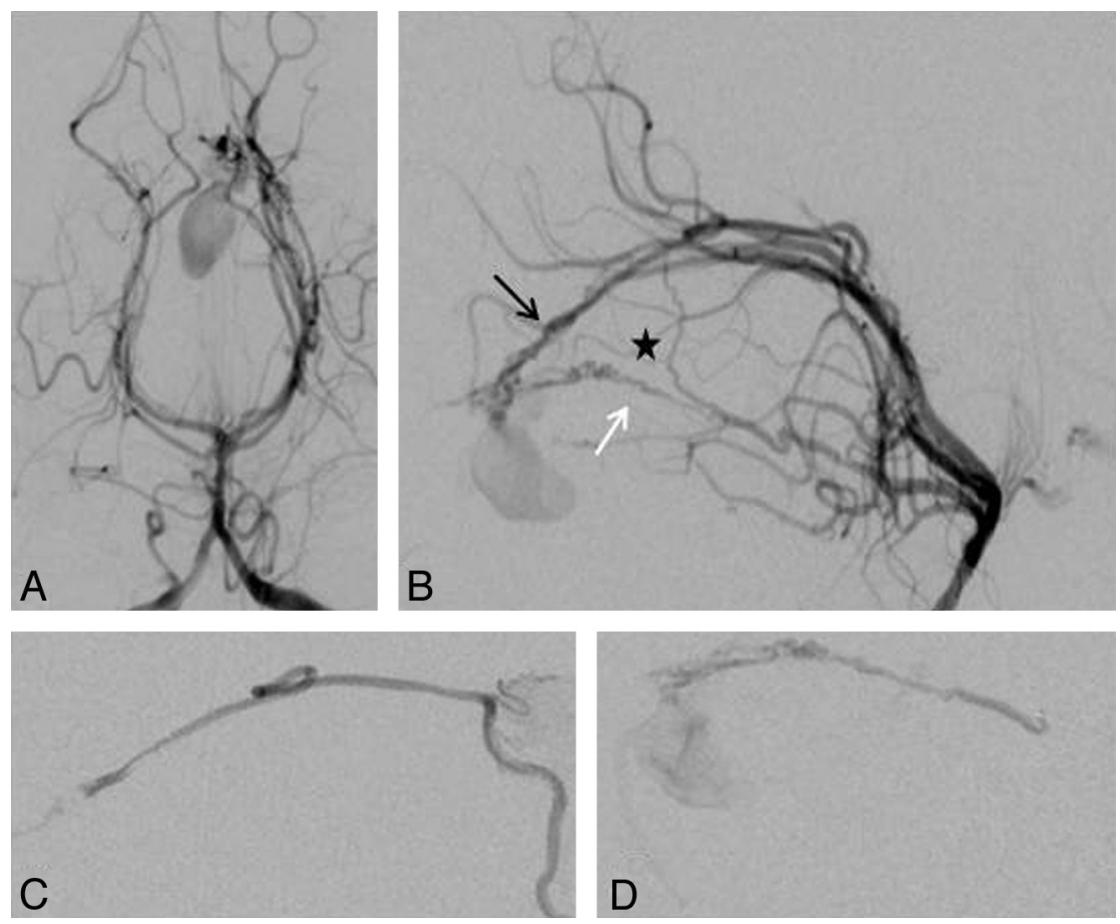

FIG 4. Falx cerebelli TDAVF (patient 1). Injections of the left vertebral artery in anteroposterior (A) and lateral $(B)$ views and superselective injection of the ADS $(C)$ and medial dural-tentorial branch of the SCA (D). The fistula supply arises from the left ADS (black arrow) and left medial duraltentorial branch of the SCA (white arrow). The asterisk marks a connection between these 2 arteries within the tentorium.
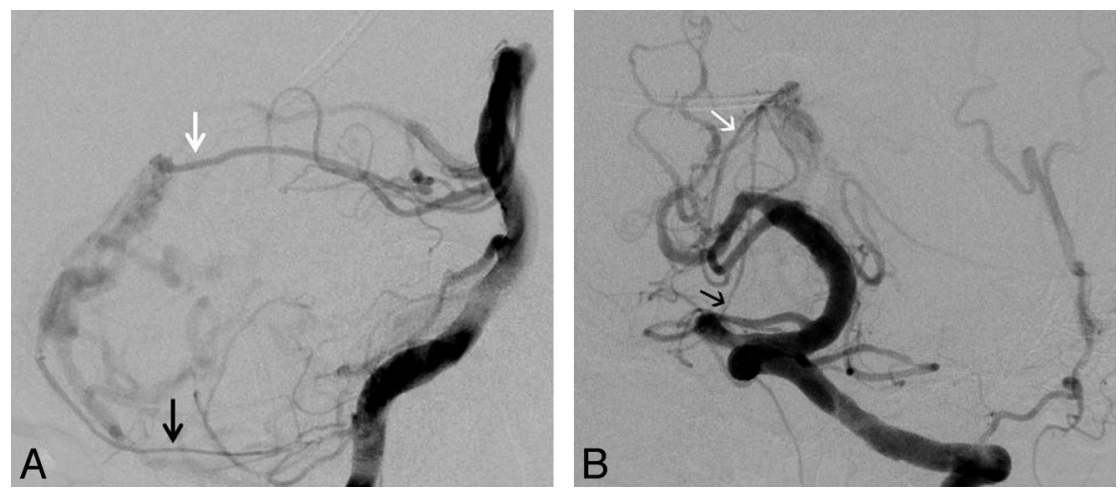

FIG 5. Falx cerebelli TDAVF (patient 2). Injections of the left vertebral artery in lateral $(A)$ and anteroposterior $(B)$ views. Arterial supply to the fistula arises, among others, from the medial dural-tentorial branch of the right SCA (white arrows) and the right posterior meningeal artery (black arrows). Additional supply from branches of the external carotid artery and the marginal tentorial artery are not shown.

\section{DISCUSSION}

\section{Classification and Venous Features}

In descriptions of TDAVFs, the term "incisura" is used ambiguously. For example, Ono et $\mathrm{al}^{22}$ called it "tentorial edge" and Wollschlaeger and Wollschlaeger, ${ }^{21}$ "free margin of the tentorium." Literally it means "opening," which would restrict the term to the hiatus and not the adjacent tentorium or its anterior free edge. ${ }^{7}$ To avoid confusion, we have simply divided TDAVFs into midline and mediolateral lesions and used conventional anatomic landmarks to separate the former.

In contrast to the more frequent DAVF of the lateral sinus located within the sinus wall ${ }^{2,5}$ and associated with sinus thrombosis, ${ }^{4,8}$ TDAVFs are typically located in the dura not directly connected to major sinuses. ${ }^{2,5}$ However, among our patients, all 4 torcular TDAVFs showed some degree of major sinus thrombosis. This observation may indicate that they had or have direct connections with the sinus and explain their more benign angioarchitecture, with 2 of the 4 being classified as Cognard type II a + b. It may also be a clue to their etiology, because prior sinus thrombosis is a probable cause for the development of lateral and sigmoid sinus DAVFs. ${ }^{8}$ Torcular TDAVFs could thus represent an intermediate entity between sinus and purely tentorial fistulas. Two torcular TDAVFs were graded as Cognard type IV, which may indicate a stage in the development of the fistula with extension into the reflected dural layers of the tentorium. In any event, all the torcular TDAVFs drained both infra- and supratentorially, so the location appears to act as an anatomic venous epicenter connecting both supra- and infratentorial compartments.

In this series, TDAVFs of the falx cerebelli were remote from a major sinus, consistently drained infratentorially, and were graded Cognard type III or IV. The extent of the falx cerebelli varies from a midline thickening of the dura to a septum extending from the inferior surface of the straight sinus to the foramen magnum. In its more complete form, it rarely extends farther anteriorly than the midpoint of the straight sinus, which is often the site of cerebellar veins connecting to the sinus (eg, declival veins). This variability could explain overlap with torcular-located lesions at 1 extreme and the solely infratentorial drainage of TDAVFs when the falx cerebelli is fully formed. It also explains the frequency of hemorrhage at presentation in the latter situation. Furthermore, because TDAVFs of the falx cerebelli were not associated with major sinus thrombosis, their etiology may differ from that of torcular and petrotentorial TDAVFs. ${ }^{5,19}$ One possible cause is trauma, because one of our patients had had an occipital craniotomy. One can speculate that the superior attachment of the falx cerebelli could act as a stress point for traumatic vessel injury.

Our observed venous drainage routes support the classification of TDAVFs proposed by Picard et al, ${ }^{5}$ who divided TDAVFs into 3 groups: 1) the tentorial marginal type with the fistulas located along the free edge of the tentorial hiatus and draining both 
Table 2: Anatomic and angiographic findings

\begin{tabular}{|c|c|c|c|c|c|}
\hline No. & Site & Location & Drainage & Grade $^{a}$ & Arterial Feeders \\
\hline 1 & Falx cerebelli & Midline & Infratentorially & IV & Meningohypophyseal trunk, ADS, SCA \\
\hline $2^{\mathrm{b}}$ & Falx cerebelli & Midline & Infra- and supratentorially & IV & $\begin{array}{l}\text { Occipital, middle meningeal, posterior meningeal } \\
\text { arteries, meningohypophyseal trunk, SCA }\end{array}$ \\
\hline 3 & Falx cerebelli & Midline & Infratentorially & IV & $\begin{array}{l}\text { Occipital, middle meningeal, posterior meningeal } \\
\text { arteries }\end{array}$ \\
\hline 4 & Torcular & Midline & Supra- and infratentorially & $\mathrm{II} a+b$ & $\begin{array}{l}\text { Occipital, middle meningeal, posterior } \\
\text { meningeal, ascending pharyngeal, arteries, } \\
\text { meningohypophyseal trunk, vertebral artery } \\
\text { branches }\end{array}$ \\
\hline 5 & Falx cerebelli & Midline & Infratentorially & IV & PICA, posterior meningeal artery \\
\hline 6 & Petrotentorial right & Right & Infratentorially & IV & $\begin{array}{l}\text { Middle meningeal, ascending pharyngeal arteries, } \\
\text { meningohypophyseal trunk, AICA }\end{array}$ \\
\hline 7 & Torcular & Midline & Supra- and infratentorially & $\mathrm{II} a+b$ & Occipital, middle meningeal arteries, ADS, SCA \\
\hline 8 & Torcular & Midline & Infra- and supratentorially & IV & $\begin{array}{l}\text { Occipital, posterior meningeal arteries, } \\
\text { meningohypophyseal trunk, ADS, SCA } \\
\text { vertebral artery branches }\end{array}$ \\
\hline 9 & Falx cerebelli & Midline & Infratentorially & IV & Occipital middle meningeal, falcine arteries \\
\hline 10 & Falx cerebelli & Midline & Infratentorially & III & Vertebral artery branches, PICA, SCA \\
\hline 11 & Falx cerebelli & Midline & Infratentorially & IV & $\begin{array}{l}\text { Occipital, middle meningeal, posterior meningeal } \\
\text { arteries, PICA, ADS }\end{array}$ \\
\hline 12 & Petrotentorial left & Left & Infra- and supratentorially & $\mathrm{II} a+b$ & $\begin{array}{l}\text { Occipital, middle meningeal, falcine, ascending } \\
\text { pharyngeal arteries, meningohypophyseal } \\
\text { trunk, inferolateral trunk, AICA }\end{array}$ \\
\hline 13 & Torcular & Midline & Supra- and infratentorially & IV & $\begin{array}{l}\text { Occipital, middle meningeal, posterior meningeal } \\
\text { arteries, meningohypophyseal trunk }\end{array}$ \\
\hline
\end{tabular}

${ }^{a}$ According to Cognard et al. ${ }^{20}$

${ }^{\mathrm{b}}$ Previous surgery.

Table 3: Treatments

\begin{tabular}{|c|c|c|c|c|c|c|}
\hline No. & $\begin{array}{l}\text { Method of } \\
\text { Treatment }\end{array}$ & Embolic Material & $\begin{array}{l}\text { No. of Embolized } \\
\text { Arterial Feeders }\end{array}$ & Route & $\begin{array}{c}\text { EVT } \\
\text { Sessions } \\
\end{array}$ & Complications \\
\hline 1 & EVT & Glubran, Onyx & 2 & Transarterial & 1 & None \\
\hline 2 & EVT & Onyx & 1 & Transarterial & 1 & None \\
\hline 3 & EVT & Onyx & 1 & Transarterial & 1 & None \\
\hline 4 & EVT & Coils, Onyx & 1 & $\begin{array}{l}\text { Coils, transvenous; Onyx, } \\
\text { transarterial }\end{array}$ & 2 & Dissection \\
\hline 5 & EVT & 3 Coils & 1 & Transarterial & 1 & None \\
\hline 6 & EVT & Glubran, Onyx & 2 & Transarterial & 1 & Perforation \\
\hline 7 & EVT & Onyx & 1 & Transarterial & 1 & None \\
\hline 8 & EVT & Onyx & 2 & Transarterial & 2 & None \\
\hline 9 & $\begin{array}{l}\text { 1) Surgery 2) EVT after } \\
\text { recurrence }\end{array}$ & Glubran, Onyx & 6 & Transarterial & 3 & Microcatheter rupture \\
\hline 10 & $\begin{array}{l}\text { Surgery after failed } \\
\text { EVT }\end{array}$ & None & N/A & $\mathrm{N} / \mathrm{A}$ & 1 & None \\
\hline 11 & EVT & Glubran to flow aneurysm & 1 & Transarterial & $2^{\mathrm{a}}$ & None \\
\hline 12 & EVT & Onyx, coils & 2 & Both & 3 & Microcatheter rupture \\
\hline 13 & EVT & Onyx & 1 & Transarterial & 1 & None \\
\hline
\end{tabular}

Note:-N/A indicates not applicable; EVT, endovascular treatment.

${ }^{a}$ Incomplete Onyx embolization 4 years previously at another hospital; fistula then already present.

supra- and infratentorially, 2) the tentorial lateral type adjacent to the lateral sinus and draining to supratentorial veins, and 3) the tentorial medial type with fistulas sited adjacent to the torcular and straight sinuses draining to the infratentorial draining system. Lawton et $\mathrm{al}^{7}$ proposed a classification with 6 anatomic locations and venous drainage patterns. This classification was based on a larger series of 31 patients and separates midline lesions into Galenic, straight sinus, and torcular. The last 2 have drainage patterns similar to those of our falx cerebelli and torcular subtypes.

\section{Arterial Characteristics}

The tentorium derives its principal arterial blood supply from tentorial branches of the ICA and dural branches of the vertebral artery and external carotid artery. These arterial systems are men- ingeal or dural and are usually identifiable on angiography in the nonpathologic state. Additional transarachnoid supply from the primarily pial arteries, such as the cortical branches of the PICA and contributions to the subarcuate plexus at the internal acoustic meatus from the AICA, ${ }^{9}$ is less evident, unless abnormally hypertrophied. Whether such transarachnoid arterial traffic is "normal" or only develops in response to the development of a DAVF is difficult to establish in vivo, and we generally rely on postmortem descriptions. The identification of a tentorial branch of the posterior cerebral artery, the ADS, was only after its enlargement in response to pathology. ${ }^{21}$ We assume that this explains the development of the medial dural-tentorial branch of the SCA identified in our patients. Both arteries appear to supply medially sited 
Table 4: Clinical and anatomic outcomes

\begin{tabular}{|c|c|c|}
\hline No. & Clinical Result & Anatomic Result \\
\hline 1 & $\begin{array}{l}\text { Died } 2 \text { weeks later due to edema } \\
\text { with brain stem compression }\end{array}$ & Cure \\
\hline 2 & Cure & Cure \\
\hline 3 & Improved & Cure \\
\hline 4 & Improved & Subtotal occlusion \\
\hline 5 & $\begin{array}{l}\text { Died due to pulmonary edema } 8 \\
\text { months later }\end{array}$ & Subtotal occlusion \\
\hline 6 & Improved & Subtotal occlusion \\
\hline 7 & Cure & Cure \\
\hline 8 & Improved & Subtotal occlusion \\
\hline 9 & Improved & Subtotal occlusion \\
\hline 10 & Unchanged & Cure (surgery) \\
\hline 11 & $\begin{array}{l}\text { Residual symptoms (treatment } \\
\text { ongoing) }\end{array}$ & PICA aneurysm occluded \\
\hline 12 & Improved & Subtotal occlusion \\
\hline 13 & Cure & Cure \\
\hline
\end{tabular}

DAVFs. The characteristics of the arterial supply to DAVFs in this study helped to define both midline and mediolateral fistulas as tentorial and proved crucial for endovascular therapy planning. Thus, we suggest that the type of feeding artery and the venous drainage should be used to categorize subtypes of TDAVF.

\section{Medial Dural-Tentorial Branch of the SCA}

The course and cerebral structures supplied by the SCA are described in standard anatomic texts and comprehensive reviews, but these do not include a supply to the tentorial dura. ${ }^{19-22} \mathrm{Al}-$ though a transcisternal branch to the dura of the tentorial hiatus has been inconsistently described in anatomic studies, ${ }^{22-25}$ this vessel has been mentioned in case reports of TDAVFs without being fully characterized. ${ }^{2,4,7,19,26}$ Recently, a branch from the SCA was observed during surgery for a TDAVF but could not be identified on angiography. ${ }^{27}$

Various names being given to this poorly defined medial dural-tentorial artery of the SCA include "meningeal artery" or "tentorial artery" of the SCA, ${ }^{2,4,7,19,26}$ and some authors appear to have confused this artery with the ADS. ${ }^{7}$ The ADS is described as arising from the posterior cerebral artery ${ }^{19}$ and, therefore, runs above the tentorium, so it should be easily differentiated from the medial dural-tentorial branch of the SCA. However, artery-toartery anastomoses can develop between these arteries within the tentorium (Fig 4) due to the rich dural arterial network. ${ }^{28}$ Such connections are common in this vascular network, and in 2 patients, we further observed connecting branches between the marginal tentorial artery and the medial dural-tentorial branch of the SCA.

The medial dural-tentorial branch of the SCA was a common feature of midline TDAVFs. It is surprising that it has not found its own nomenclature in anatomic descriptions of the blood supply to the tentorium. Its omission from reviews focusing on the anatomic organization of the dura ${ }^{19,23}$ may be due to its absence or small size in the nonpathologic state. It arises from the superior or rostral trunk of the SCA and traverses the ambiens cistern under the tentorium, which it enters in the posterior half of the incisura. In our patients, it showed a characteristic course on lateral DSA, running in an almost straight or only slightly concave downwards curve from anterior to posterior, and on anteropos- terior DSA, it curves medially to reach the midline posterior to the incisura. Its course thus parallels that of the marginal tentorial artery. Fistulous contributions by transarachnoid anastomoses from primarily cerebral arteries are well-recognized, ${ }^{5}$ and we considered whether these might occur superficial to the tentorium (ie, that the artery runs inferior to the tentorium directly to the fistula site, but the observed anastomosis with the ADS [Fig 4] demonstrates a substantial transdural course).

Regardless of the explanation for its under-recognition, this study suggests that the medial dural-tentorial branch of the SCA should be expected to supply midline TDAVFs posterior to the incisura. Selective angiography may be necessary for confirmation of its origin from the SCA and, as in one of our patients, can be used for embolization (Fig 4). Thus, recognition of its contribution is essential for diagnosis, endovascular treatment planning, and possibly in posterior fossa surgery. ${ }^{27}$

\section{CONCLUSIONS}

Endovascular therapy was effective in this series, and arteriography was essential for diagnosis and planning. The medial duraltentorial artery of SCA supplies midline TDAVFs, has a characteristic course along the tentorium, and should be included in future descriptions of tentorial blood supply.

\section{ACKNOWLEDGMENTS}

We thank Alison Clarke for help in preparing the manuscript, Henry Byrne for drawing Fig 1, and our colleagues at the John Radcliffe Hospital for their support.

Disclosures: James V. Byrne-UNRELATED: Board Membership: Codman Neurovascular, Comments: Scientific advisory board member, Grants/Grants Pending: Balt International, ${ }^{*}$ Siemens, ${ }^{*}$ Payment for Lectures (including service on Speakers Bureaus): Siemens, Royalties: Springer-Verlag, Oxford University Press, Comments: proportion of book sales. *Money paid to the institution.

\section{REFERENCES}

1. Kajita Y, Miyachi S, Wakabayashi T, et al. A dural arteriovenous fistula of the tentorium successfully treated by intravascular embolization. Surg Neurol 1999;52:294-98

2. Zhou LF, Chen L, Song DL, et al. Tentorial dural arteriovenous fistulas. Surg Neurol 2007;67:472-81

3. Wajnberg E, Spilberg G, Rezende MT, et al. Endovascular treatment of tentorial dural arteriovenous fistulae. Interv Neuroradiol 2012;18:60-68

4. van Lindert E, Hassler W, Kühne D, et al. Combined endovascularmicrosurgical treatment of tentorial-incisural dural arteriovenous malformations: report of five cases. Minim Invasive Neurosurg 2000;43:138-43

5. Picard L, Bracard S, Islak C, et al. Dural fistulae of the tentorium cerebelli: radioanatomical, clinical and therapeutic considerations. J Neuroradiol 1990;17:161-81

6. Tomak PR, Cloft HJ, Kaga A, et al. Evolution of the management of tentorial dural arteriovenous malformations. Neurosurgery 200352 : $750-60$, discussion 760-62

7. Lawton MT, Sanchez-Mejia RO, Pham D, et al. Tentorial dural arteriovenous fistulae: operative strategies and microsurgical results for six types. Neurosurgery 2008;62(suppl 1):110-24

8. Harrigan MR, Deveikis JP. Handbook of Cerebrovascular Disease and Neurointerventional Technique. New York: Humana Press; 2009

9. Byrne JV. Tutorials in Endovascular Neurosurgery and Interventional Neuroradiology. Berlin: Springer-Verlag; 2012

10. Davies MA, ter Brugge $K$, Willinsky $R$, et al. The natural history and 
management of intracranial dural arteriovenous fistulae. Part 2. Aggressive lesion. Interv Neuroradiol 1997;3:303-11

11. Biondi A, Ricciardi GK, Clemenceau S, et al. Dural arteriovenous fistulas of the tentorial margin: angiographic aspects and endovascular treatment. In: Proceedings of the 41st Meeting of the American Society of Neuroradiology, Washington, DC. April 28-May 2, 2003

12. Grigorian IA, Stepanian MA. Trigeminal neuralgia and tentorial dural arteriovenous malformation [in Russian]. Zh Vopr Neirokhir Im N N Burdenko 2010;46-51

13. Mariniello G, Briganti F, Vergara P, et al. Dural tentorial arteriovenous fistula causing isolated trochlear nerve palsy: remission after endovascular embolization. J Neurointerv Surg 2012;4:e5

14. Matsushige T, Nakaoka M, Ohta K, et al. Tentorial dural arteriovenous malformation manifesting as trigeminal neuralgia treated by stereotactic radiosurgery: a case report. Surg Neurol 2006; 66:519-23

15. Rahme R, Ali Y, Slaba S, et al. Dural arteriovenous malformation: an unusual cause of trigeminal neuralgia. Acta Neurochir (Wien) 2007; 149:937-41, discussion 941

16. Takeshita T, Toyoda K, So G, et al. A tentorial dural arteriovenous fistula presenting progressive myelopathy: a case report [in Japanese]. Brain Nerve 2011;63:611-15

17. Tubbs RS, Nguyen HS, Shoja MM, et al. The medial tentorial artery of Bernasconi-Cassinari: a comprehensive review of its anatomy and neurosurgical importance. Acta Neurochir (Wien) 2011;153: 2485-90

18. Shin M, Kurita H, Tago M, et al. Stereotactic radiosurgery for ten- torial dural arteriovenous fistulae draining into the vein of Galen: report of two cases. Neurosurgery 2000;46:730-33

19. Lewis AI, Tomsick TA, Tew JM Jr. Management of tentorial dural arteriovenous malformations: transarterial embolization combined with stereotactic radiation or surgery. J Neurosurg 1994; 81:851-59

20. Cognard C, Gobin YP, Pierot L, et al. Cerebral dural arteriovenous fistulas: clinical and angiographic correlation with a revised classification of venous drainage. Radiology 1995;194:671-80

21. Wollschlaeger PB, Wollschlaeger G. An infrantentorial meningeal artery [in German]. Radiologe 1965;5:451-52

22. Ono M, Rhoton AL Jr., Barry M. Microsurgical anatomy of the region of the tentorial incisura. J Neurosurg 1984;60:365-99

23. Hardy DG, Peace DA, Rhoton AL Jr. Microsurgical anatomy of the superior cerebellar artery. Neurosurgery 1980;6:10-28

24. Martins C, Yasuda A, Campero A, et al. Microsurgical anatomy of the dural arteries. Neurosurgery 2005;56(suppl 2):211-51

25. Stranding S. Gray's Anatomy: The Anatomical Basis of Clinical Practice, London, UK: Churchill Livingstone; 2008

26. Miyagi $\mathrm{K}$, Iwasa $\mathrm{H}$, Yoshimizu N, et al. Tentorial dural arteriovenous malformation: a case report (author's transl) [in Japanese]. No Shinkei Geka 1976;4:1185-91

27. Weil AG, McLaughlin N, Denis D, et al. Tentorial branch of the superior cerebellar artery. Surg Neurol Int 2011;2:71

28. Newton TH, Cronqvist S. Involvement of dural arteries in intracranial arteriovenous malformations. Radiology 1969;93:1071-78 